J. Lake Sci. (湖泊科学), 2011, 23(3):311-320

http: //www.jlakes.org. E-mail: jlakes@niglas.ac.cn

(c) 2011 by Journal of Lake Sciences

\title{
青藏高原内陆湖泊变化的遥感制图"
}

\author{
李均力 ${ }^{1,2}$, 盛永伟 ${ }^{2}$, 骆剑承 ${ }^{3}$, 沈占峰 $^{3}$ \\ (1: 中国科学院新疆生态与地理研究所, 乌鲁木齐 830011 ) \\ (2: 加利福尼亚州大学洛杉矶分校地理系, 洛杉矶 90095$)$ \\ (3: 中国科学院遥感应用研究所,北京 100101)
}

\begin{abstract}
摘 要: 青藏高原上的内陆湖泊群是气候变化的敏感指示器, 获取近几十年来湖泊变化的动态信息对研究区域气候及环 境变化具有重要的意义. 本文讨论了多时相遥感湖泊变化研究中的几个关键问题一一湖泊变化季节性因素、湖泊变化信 息的提取以及大区域湖泊变化的分析方法,并利用 Landsat 长时间序列遥感数据,制作青藏高原 $1970 \mathrm{~s}, 1990 \mathrm{~s}, 2000 \mathrm{~s}$ 和 2009 年四个时段的湖泊分布图及其湖泊变化图, 分析三十多年来内陆封闭流域内湖泊变化的时空特征. 研究结果表明, Landsat MSS/TM/ETM ${ }^{+}$多时相数据在对 $0.1 \mathrm{~km}^{2}$ 以上湖泊进行变化分析时能取得较好的结果. 湖泊在一年之内最稳定的 时段为 9-12 月,其最大湖泊面积变化率不超过 2\%. 从湖泊变化的时间过程来看,湖泊总面积在 $1970 \mathrm{~s}-1990 \mathrm{~s}$ 呈萎缩趋 势, 在 $1990 \mathrm{~s}-2009$ 年剧烈扩张, $1970 \mathrm{~s}-2009$ 年全时段湖泊总面积增长 $27.3 \%$. 从空间分布来看, 湖泊变化具有明显的区 域分布特性,藏北㒸塘高原区湖泊出现先萎缩后扩张的变化,色林错及周边区域湖泊处于持续扩张的状态, 而冈底斯山 北麓的高山深谷湖泊则在近三十多年来保持相对稳定的状态.
\end{abstract}

关键词: 青藏高原;湖泊变化;湖泊制图;时空变化分析;遥感

\section{Remotely sensed mapping of inland lake area changes in the Tibetan Plateau}

\author{
LI Junli ${ }^{1,2}$, SHENG Yongwei ${ }^{2}$, LUO Jiancheng ${ }^{3}$ \& SHEN Zhanfeng ${ }^{3}$ \\ (1: Xinjiang Institute of Ecology and Geography, Chinese Academy of Sciences, Urumqi 830011, P. R. China) \\ (2: Department of Geography, University of California, Los Angeles (UCLA), Los Angeles 90095, USA) \\ (3: Institute of Remote Sensing Applications, Chinese Academy of Sciences, Beijing 100101, P. R. China)
}

Abstract: Numerous inland lakes of the Tibetan Plateau play sensitive indicators to climate change, and mapping and monitoring these lakes would facilitate our understanding of regional climate and environmental changes. The paper is mainly focused on issues of lake mapping and detecting techniques based on multi-temporal remote sensing imagery, and the differences of lake seasonal and decadal changes were also analyzed. With a series of Landsat MSS/TM/ETM ${ }^{+}$imagery in recent 30 years, Tibetan lakes in 1970s, 1990s, 2000s and 2009 are mapped and their changes are detected temporally and spatially. The lake mapping results showed that Landsat datasets have a good performance on lake area mapping whose lake areas are larger than $0.1 \mathrm{~km}^{2}$. There are minor seasonal variations of lake areas from September to December, so that the season could be taken as the best time periods for lake area mapping. The maximum rate of lake area change is less than $2 \%$. Temporally, lakes presented a shrinking trend during $1970 \mathrm{~s}-$ $1990 \mathrm{~s}$, while an expanding trend during $1990 \mathrm{~s}-2009$, and the total lake area change rate during $1970 \mathrm{~s}-2009$ is $27.3 \%$. Spatially, lakes changing rates varied with their spatial locations: lakes in Qiangtang Plateau show dramatic shrinking changes during 1970s - 1990s while expanding changes during 1990s - 2009; lakes in Selin Co Basin and its surrounding areas show expanding changes in the past 30 years, while lakes in northern valley of the Kangdese and southern Kunlun Mountains remain relatively stable.

Keywords: Tibetan Plateau; lake area changes; lake mapping; temporal and spatial changes; remote sensing

* 中国科学院西部博士资助项目 (XBBS200809) 和美国宇航局项目 (NNX06AE58G) 联合资助. 2010 - 09-28 收稿; 2010-12-26 收修改稿. 李均力, 男, 1980 年生, 博士, 助理研究员; E-mail: lijl@ ms. xjb. ac. cn. 
青藏高原是我国湖泊分布最为密集的地区之一, 高原上的湖泊地处偏远, 较少受人类活动的影响, 湖泊 的萎缩或扩张能够真实地反映区域气候与环境的变化状况, 是全球气候变化的敏感指示器 ${ }^{[1]}$. 内陆湖泊是 青藏高原湖泊的主要形式, 广泛分布在芫塘高原数量众多的封闭内流流域内 ${ }^{[1-2]}$. 在严寒干旱、降雨稀少和 蒸发强烈等特殊的高原气候背景下, 降水、冰川融水、地下水以及冻土中的水分释放是内陆湖泊最主要的几 种补给形式 ${ }^{[3]}$. 封闭内陆流域无外流, 流域内湖泊水位和面积的变化可直观地反映流域内水量平衡的变化 过程 ${ }^{[4]}$. 了解近几十年来青藏高原内陆湖泊的变化规律对研究气候变化背景下的区域水资源变化及环境变 迁具有重要意义 ${ }^{[5]}$.

遥感是快速、经济地获取湖泊变化信息的有效手段,已广泛应用于各种湖泊调查与湖泊变化研究. 不少 学者借助遥感解译获取青藏高原典型湖泊的动态变化信息, 并分别从冰川融水、冻土、气温与降水等因素研 究近几十年来局部区域湖泊萎缩或扩张的机理 ${ }^{[6-15]}$. 近年来,武慧智、张继承等使用遥感数据对高原全区域 的湖泊遥感提取, 分析不同时段湖泊的总体变化趋势和区域变化特征 ${ }^{[16-17]}$. 然而, 大多数研究主要通过遥感 解译和人工编辑的方式获取局部区域内部分湖泊多时相变化信息, 对大区域、湖泊众多的青藏高原内陆地 区则需要借助遥感自动化信息提取的技术快速获取湖泊信息 ${ }^{[18-19]}$. 目前, 大区域湖泊变化信息的提取依然 存在不少难点. 由于遥感存档数据获取困难以及云的干扰, 很难获取覆盖大区域不同时段的遥感数据, 为此 不少相关研究并未严格界定湖泊变化的季节性差异. 而在藏北腹地, 部分内陆湖泊的湖泊面积在其丰水期 与枯水期的变化可达 $50 \%$ 以上 ${ }^{[20]}$, 对该区域进行长时间序列的湖泊变化研究需区分湖泊的季节变化和阶 段性变化. 另外, 内陆地区湖泊众多, 湖泊变化频繁, 经常出现湖泊新增、消失、合并、分裂的情形, 如何快速 地比较和分析区域湖泊动态变化特征,也是大区域、长时间序列湖泊动态变化研究的关键.

本文主要研究海量多时相 Landsat 系列遥感数据支持下的青藏高原内陆湖泊变化的信息提取技术与分 析方法, 为长时间序列的湖泊变化研究提供准确的湖泊制图信息. Landsat 系列卫星 (Landsat 1-5 MSS、Landsat 4-5 TM 和 Landsat $7 \mathrm{ETM}^{+}$) 已运行近 40 年,积累了丰富的遥感存档数据,具备了短时段、重复覆盖同一 地区的能力. Landsat 的历史存档数据已于 2008 年免费向公众发布 ${ }^{[21]}$, 为大区域、长时段的湖泊变化分析提 供了数据基础. 为此,本文采用 1976 年、1990 年、2000 年和 2009 年多时相 Landsat 存档数据提取青藏高原内 陆地区四个不同时期的湖泊变化信息,讨论内陆湖泊变化分析中的季节性因素与制图精度, 并以封闭内流 流域为单元, 分析湖泊变化的时间过程和空间特征.

\section{1 研究区域及数据源}

本文的研究对象是青藏高原内陆地区的湖泊, 研究区域为青藏高原封闭内流流域 (图 1). 其中, 流域边 界数据来源于美国地质调查局 (USGS) 发布的 HydroSheds 产品 ${ }^{[22]}$, 主要采用 SRTM DEM (Shuttle Radar Topography Mission, Digital Elevation Model) 高程数据产品 (空间分辨率约 $90 \mathrm{~m}$ ) 提取的全球流域边界. 图中黄 线为流域边界, 红线区域为本文所选择的研究区, 是高原上空间相连的封闭流域单元集合 $\left(28^{\circ}-38^{\circ} \mathrm{N}, 78^{\circ}-\right.$ $93^{\circ} \mathrm{E}$ ), 共 268 个内流流域, 面积逾 $680000 \mathrm{~km}^{2}$, 约占大青藏高原的 $1 / 4$. 研究区域覆盖了高原上 $70 \%$ 以上的 湖泊, 绝大部分湖泊处于高原古湖泊剧烈萎缩后的古湖盆之中. 本文使用的遥感数据源为 Landsat MSS、TM 和 $\mathrm{ETM}^{+}$, 共约 200 景影像. 根据在不同时段 Landsat 可用存档数据的多寡,使用数据存档数量较多地区的 $\mathrm{ETM}^{+}$和 TM 数据获取该地区湖泊在一年之内的湖泊季节性变化信息; 采用 1976 年 MSS、1990 年 TM、2000 年 $\mathrm{ETM}^{+}$和 2009 年 TM 四期数据提取湖泊的阶段性变化信息. 由于云、雪覆盖、数据缺乏或数据质量的因 素, 部分湖泊被遮挡或难以提取, 这些地区采用了多景相近年份相同季节的数据, 以形成 1970s、1990s、2000s 和 2009 年覆盖全区域的时间序列数据.

\section{2 研究方法}

\section{1 遥感湖泊信息的提取}

由于研究区域范围广、数据量大,湖泊信息提取方法需尽可能做到高精度、自动化, 以减少湖泊编辑后 处理的工作量. 高原上湖泊的理化特性各异,不同湖泊的光谱差异较大,传统的阈值分割或分类方法较难获 取较精确的边界信息 ${ }^{[18]}$. 为此,本文采用了一种 “全域一局部” 自适应阈值分割的湖泊提取方法 ${ }^{[14]}$, 以水体指 


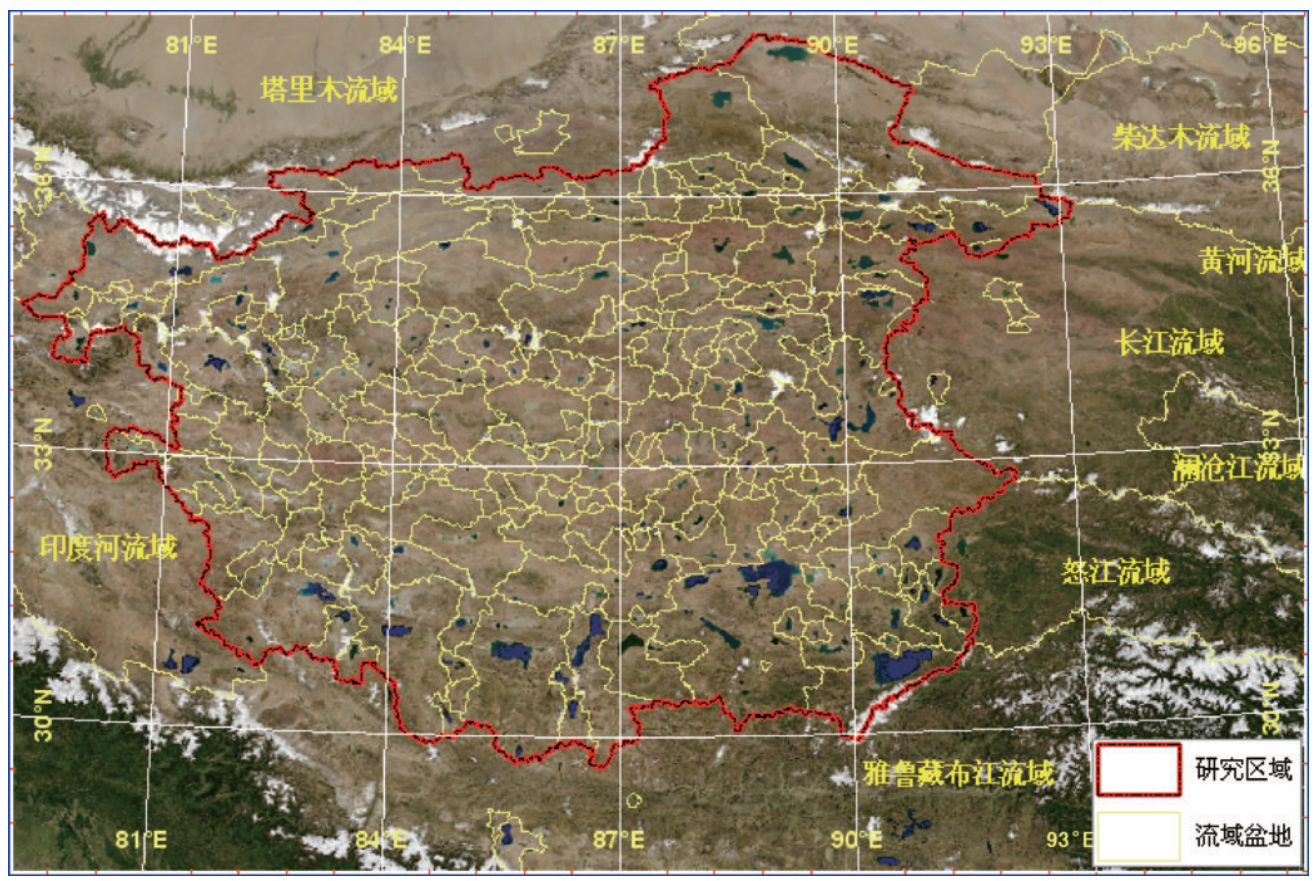

图 1 青藏高原内陆湖泊研究区

Fig. 1 Study area of inland lakes in the Tibetan Plateau

数 NDWI(Normalized Difference Water Index) 作为湖泊信息的提取指标, 采用直方图阈值分割的方法对 NDWI 图像进行全域分割,初步分离出水体和背景信息; 然后针对每个水体单元, 在水体单元和缓冲区组成 的区域内进行局域阈值分割, 并通过迭代的方法确定其最佳阈值, 获取精确的水体边界. 具体方法与流程 见文献 ${ }^{[19]}$. 与其它湖泊信息提取方法相比,该方法针对不同湖泊的物理特性,自动寻找最佳分割阈值, 提 高了湖泊信息提取的效率和制图精度; 同时还能有效区分山体阴影、融化的冰川等混淆像元, 大大减少了 编辑的工作量. 在遥感数据质量理想的情况下, 该方法理论上可对 5 个像元以上的湖泊单元进行高精度 提取 ${ }^{[19]}$.

湖泊栅格信息提取结果还需转换为矢量格式,并在 ArcGIS 中进行编辑和质量验证,删除河流单元和混 淆的非湖泊单元, 得到单幅影像的湖泊矢量图层. 然而按照统一的坐标投影对所有的湖泊图层进行重投影, 并拼合同一时期的湖泊图层,剔除圥余信息,得到完整的多时段湖泊制图信息. 由于本文重在分析湖泊的面 积变化,为了保证重投影前后湖泊面积保持不变,这里采用兰伯特方位等面积投影 (中央经线 $87^{\circ} \mathrm{E}$,起始纬 度 $33^{\circ} \mathrm{N}$ ) 作为统一的投影坐标系统.

\section{2 多时相湖泊变化信息的生成}

由于多时相遥感数据空间分辨率的不同以及数据质量的不同,获取的湖泊最小单元也不相同. 在进行 多时相湖泊图层的变化分析之前,还需统一不同湖泊图层的制图精度, 以减少非变化信息对多时相湖泊分 析的干扰. 统一制图精度后, 采用 ArcGIS 空间分析工具比较两个不同时相 $T_{1}$ 和 $T_{2}\left(T_{1}<T_{2}\right)$ 湖泊图层的面 积变化. 这里采用空间关联功能建立这两个图层的关联,并连接对应湖泊的空间和属性信息, 以方便湖泊面 积的统计与比较. 湖泊在两个时相的空间关系有以下几种: (1) $T_{1}$ 时期的一个湖泊对应 $T_{2}$ 时期的一个湖 泊,空间上为一一对应,此时湖泊的变化为两个时期湖泊面积差, 湖泊可能出现萎缩或扩张的变化; (2) $T_{1}$ 时期有湖泊而 $T_{2}$ 时期无湖泊,表示湖泊已干涸, 面积变化率设为 - 100\% ; (3) $T_{2}$ 时期有湖泊而 $T_{1}$ 时期无 湖泊,为新增湖泊,变化率设为 $10000 \%$; (4) $T_{1}$ 时期 $M$ 个湖泊与 $T_{2}$ 时期 $N$ 个湖泊对应, 表明湖泊出现分裂 或合并运动,湖泊的变化为 $T_{1}$ 时期 $M$ 个湖泊面积和与 $T_{2}$ 时期 $N$ 个湖泊面积和之差; 当 $M=1$ 且 $N>1$ 表示 
湖泊分裂, 主要发生在湖泊萎缩的时期; $M>1$ 且 $N=1$ 表示湖泊合并, 主要发生在湖泊扩张的时期; 而当 $M$ $>1$ 且 $N>1$ 时, 表示湖泊的分裂与合并过程在同时进行. 在建立空间关系确定后, 两个时期关联湖泊的面积 差作为变化的湖泊面积, 并计算面积变化率 $R$ :

$$
R=\left(A_{\mathrm{T} 2}-A_{\mathrm{T} 1}\right) \times 100 \% / A_{\mathrm{T} 1}
$$

式中, $A_{\mathrm{T} 1} 、 A_{\mathrm{T} 2}$ 分别为 $T_{1}$ 和 $T_{2}$ 时段关联湖泊的面积之和, $R$ 为湖泊面积变化率. 由此, 湖泊变化可分为 5 个类 型: 干涸的湖泊 $(R=-100 \%)$ 、萎缩的湖泊 $\left(R<-R_{0}\right)$ 、稳定的湖泊 $\left(-R_{0} \leqslant R \leqslant R_{0}\right)$ 、扩张的湖泊 $\left(R>R_{0}\right)$ 和新增的湖泊 $(R=10000 \%)$.

\section{3 多时相内陆湖泊变化分析}

本文主要从时间变化过程和空间变化特征的角度分析青藏高原内陆区的湖泊变化. 由于研究区域内湖 泊众多,湖泊类型及水源补给存在较大的差异,湖泊的变化呈现多样化,同一地区的不同湖泊就可能同时出 现扩张或萎缩的情形, 很难分析湖泊变化的区域空间模式. 内陆封闭流域无外流, 流域内水量的盈亏可直接 表现为流域内湖泊面积的扩张与萎缩. 为此, 本文按照流域单元对湖泊进行区域划分, 以封闭流域为单元, 统计和比较每个流域内湖泊总面积的变化, 探讨湖泊变化的时空特征.

\section{3 内陆湖泊的季节性变化}

由于青藏高原内陆湖泊的水源补给主要有降水、冰川融水、地下水和冻土融化的水分. 而这些水源补给 存在显著的季节性差异, 春夏季处于丰水期, 而秋冬季处于枯水期, 部分湖泊在一年之内就可能发生较大的 面积变化. 为此, 长时段湖泊面积的比较需要选择湖泊相对稳定的季节, 尽可能地减少季节性变化对阶段性 变化分析的干扰. 通过对研究区内部分湖泊一年内的面积变化时间序列数据的分析, 找出一年内湖泊面积 最为稳定的时段, 确定湖泊在该时段的最大面积变化率, 并以此作为区分湖泊的季节性变化与阶段性变化 的依据.

\section{1 湖泊的季节性变化}

气象资料表明,青藏高原地区的冰冻期为 10 月至次年 5 月 ${ }^{[23]}$, 同时也是降水与蒸发较少的时期, 大部分湖泊在此期间的面积变化不大. 而由于降水稀少,遥感观测较少受到云的干扰. 根据 Landsat 存 档记录可知青藏高原区 10-11 月间以后有较多数量的无云 Landsat 数据. 此外, 通过对 Landsat 数据的 判读分析,发现 10-11 月绝大部分湖泊处于未结冰的状态, 12 月底依然有不少湖泊未冰冻, 这主要是 因为研究区内的湖泊大多数为盐湖或咸水湖, 湖水的冰点较低, 并且羌塘高原北部不少湖泊的部分水 源为热泉或温泉等地下水 ${ }^{[1]}$, 一定程度上延缓了湖水结冰的时间. 然而由于研究区域过大, 部分区域 数据无 10-11 月份遥感数据, 这里对观测日期分别向前和向后扩展 1 个月,以 $9-12$ 月份扩展选择全 区域的遥感数据.

为了分析湖泊在 1 年之内的季节性变化和 $9-12$ 月份最大面积变化率, 本文选择了 8 个典型的湖泊进 行分析,分别计算 9-12 月单季和全年的最大面积变化率(表 1), 结果表明湖泊的全年面积变化率要远远大 于单季变化率, 不同湖泊的全年变化率差异较大, 从 $1.1 \%$ 到 $101.0 \%$ 不等, 而单季变化率差异相对较小, 大 多在 $1 \%$ 以内, 最大仅为 $1.75 \%$. 全年变化率最大的是万泉湖 (尾问湖), 在 2000 年 1 月至 11 月面积扩大了 一倍,而 $9-12$ 月的单季变化率不及 $1 \%$. 温泉湖 (吞吐型湖泊,位于万泉湖上游), 全年变化率为 $11.7 \%$, 但 单季变化率却仅为 $1.41 \%$, 仅为全年变化率的 $1 / 8$.

上述结果表明,尽管内陆湖泊在一年之内的面积变化剧烈,而在 $9-12$ 月却能保持面积的相对稳定. 因 此, 长时段的湖泊变化分析需考虑数据获取的季节, 尽量选择季节相同的数据. $9-12$ 月湖泊最大面积变化 率不超过 $2 \%$, 且远小于全年变化率, 把它作为长时段湖泊变化分析的时段是比较合理的. 同时本文还选择 变化率 $R_{0}=2 \%$ 作为湖泊单季变化与长时段变化的分界点, 若长时段湖泊面积变化率的绝对值低于 $R_{0}$, 则 认为湖泊是稳定的, 湖泊面积变化处于正常变化的扰动范围内; 若高于 $R_{0}$ 则认为湖泊发生了萎缩或扩张的 阶段性变化. 
表 1 典型湖泊的季节性变化

Tab. 1 Seasonal variations of typical inland lakes

\begin{tabular}{|c|c|c|c|c|c|c|c|c|c|}
\hline \multirow{2}{*}{ 湖泊 } & & \multirow{2}{*}{\multicolumn{6}{|c|}{ 不同季节的湖泊面积 $\left(\mathrm{km}^{2}\right)$}} & \multicolumn{2}{|c|}{ 最大面积变化率 (\%) } \\
\hline & & & & & & & & \multirow{2}{*}{$\begin{array}{c}9-12 \text { 月 } \\
0.11\end{array}$} & \multirow{2}{*}{$\begin{array}{l}\text { 全年 } \\
3.0\end{array}$} \\
\hline 色林错 & 日期 & 20010111 & 20010212 & 20010519 & 20010722 & 20010924 & 20011111 & & \\
\hline & 面积 & 1896.22 & 1895.242 & 1905.25 & 1919.05 & 1950.04 & 1952.10 & & \\
\hline \multirow{2}{*}{ 达则错 } & 日期 & 20000304 & 2000523 & 20000726 & 2000928 & 20001014 & 20001030 & 0.21 & 2.1 \\
\hline & 面积 & 240.78 & 237.94 & 240.48 & 242.92 & 242.96 & 242.39 & & \\
\hline \multirow[t]{2}{*}{ 阿克萨钦湖 } & 日期 & 20090603 & 20090705 & 20090806 & 20090923 & 20091025 & 20091126 & 0.68 & 2.9 \\
\hline & 面积 & 224.71 & 223.41 & 222.47 & 219.77 & 218.54 & 218.28 & & \\
\hline \multirow[t]{2}{*}{ 崩错 } & 日期 & 20000306 & 20000728 & 20000914 & 20001016 & 20001117 & 20001219 & 0.13 & 1.1 \\
\hline & 面积 & 141.59 & 141.69 & 140.26 & 140.16 & 140.35 & 140.11 & & \\
\hline \multirow{2}{*}{ 邦达错 } & 日期 & 20000103 & 20000510 & 20000627 & 20000915 & 20001017 & 20001204 & 1.75 & 4.4 \\
\hline & 面积 & 104.39 & 104.68 & 105.79 & 107.13 & 108.53 & 109.01 & & \\
\hline \multirow[t]{2}{*}{ 嘎仁错 } & 日期 & 20090130 & 20090607 & 20090810 & 20090927 & 20091013 & 20091114 & 0.63 & 8.1 \\
\hline & 面积 & 66.46 & 64.00 & 62.71 & 61.89 & 61.67 & 61.50 & & \\
\hline \multirow[t]{2}{*}{ 万泉湖 } & 日期 & 20000105 & 20000613 & 20000917 & 20001003 & 20011104 & - & 0.86 & 101.0 \\
\hline & 面积 & 36.39 & 35.20 & 70.76 & 70.25 & 70.16 & - & & \\
\hline \multirow{2}{*}{ 温泉湖 } & 日期 & 20000105 & 20000613 & 20000917 & 20001003 & 20011104 & - & 1.41 & 11.7 \\
\hline & 面积 & 10.44 & 10.28 & 11.33 & 11.32 & 11.48 & - & & \\
\hline
\end{tabular}

\section{2 湖泊阶段性变化的数据选择}

通过对 Landsat 存档数据不同年度、不同季节可获得的数据进行分析, 并根据降水观测资料 ${ }^{[23-24]}$, 选择 降水正常年份 1976 年、1990 年、2000 年和 2009 年遥感数据进行湖泊制图,数据的时相主要选择在 $10-11$ 月,在该时段无可选数据时再选取 9 月和 12 月的数据. 为了获取全区域覆盖的湖泊信息, 本文选择了多幅降 水条件类似的、年份相近的数据作为湖泊制图的补充. 覆盖研究区域的 Landsat 数据单期覆盖 42 景, 共 168 景, $1970 \mathrm{~s} 、 2000 \mathrm{~s}$ 和 2009 年 3 个时段的数据符合 $9-12$ 月的条件, 而 $1990 \mathrm{~s}$ 时相则选择了较多年份的数据 (表 2). 气象站点观测资料显示除 1994 年的 1 景数据以外其它 Landsat 数据都为降水正常年份获取 ${ }^{[23]}$, 而 1994 年的这景数据 (轨道为 P138R35) 位于可可西里腹地的卓乃湖与太阳湖流域, 流域内及其周边无气象观 测,水源补给主要来自冰川融水. 从普林斯顿大学发布的 $1960-2006$ 年全球 0.5 度气温与降水栅格数据 ${ }^{[24]}$ 测算,该地区 $1989-1994$ 年间的年均降水很小,分别为 $223 、 227 、 232 、 225 、 241 、 212 \mathrm{~mm}$. 因此,采用 1994 年的 数据合成 $1990 \mathrm{~s}$ 时段全区域的湖泊制图信息不会造成较大的季节差异.

\section{4 湖泊变化制图的信息取舍}

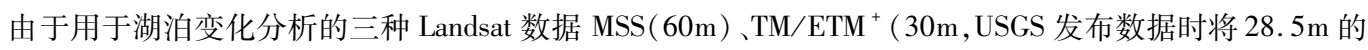
$\mathrm{ETM}^{+}$重采样为 $30 \mathrm{~m}$ ) 在空间分辨率和数据质量上存在较大的差异, 不同时期湖泊的制图精度也存在较大差 别. 从本文采用的湖泊提取方法的理论精度来看, 可获取 Landsat 影像上 5 个像元以上的湖泊单元 ${ }^{[19]}$, 对应 的 MSS、TM/ETM ${ }^{+}$最小湖泊单元面积分别为 $18000 \mathrm{~m}^{2}$ 和 $4500 \mathrm{~m}^{2}$. 因此, TM/ETM ${ }^{+}$湖泊图层中面积在 $4500-$ $18000 \mathrm{~m}^{2}$ 之间的湖泊不能参与湖泊变化分析. 从数据质量来看, 大部分 MSS 影像的信噪比远低于 TM 和 $\mathrm{ETM}^{+}$, 噪声偏重, 部分面积较小的湖泊难以自动识别. 因而需要对现有的湖泊制图结果进行取舍, 统一湖泊 制图精度,减少非变化的湖泊信息对变化分析的影响.

本文按照湖泊面积大小对四期 Landsat 湖泊图层分段统计, 比较不同时段的湖泊数量与湖泊总面积 (表 3). 从湖泊面积分段内的湖泊数量与湖泊面积的关系来看, 单个湖泊的面积越大, 处在该面积分段的湖 泊数量越少, 湖泊总面积也越大. 大于 $1 \mathrm{~km}^{2}$ 的湖泊总面积占所有总面积的 $95 \%$ 以上, 而小于 $0.1 \mathrm{~km}^{2}$ 的湖泊 虽然占总数量的半数以上, 该分段内的湖泊面积却不及总面积的 $1 \%$ (表 3 ). 从分段湖泊数目与面积来看, 四个时期内大于 $0.1 \mathrm{~km}^{2}$ 的湖泊数量与面积处于同一数量级, 而小于 $0.1 \mathrm{~km}^{2}$ 的湖泊则在湖泊数量与面积上 存在较大的差异. 
表 2 四期 Landsat 数据的时相选择

Tab. 2 Landsat data selection in the four periods

\begin{tabular}{|c|c|c|c|c|c|c|c|c|c|c|c|}
\hline \multicolumn{2}{|c|}{$\begin{array}{l}\text { WRS-2 } \\
\text { 轨道 }\end{array}$} & \multirow{2}{*}{$\begin{array}{c}\begin{array}{c}1970 \mathrm{~s} \\
\mathrm{MSS}\end{array} \\
19761111\end{array}$} & \multirow{2}{*}{$\begin{array}{c}1990 \mathrm{~s} \\
\text { TM }\end{array}$} & \multirow{2}{*}{$\begin{array}{c}2000 \mathrm{~s} \\
\mathrm{ETM}^{+} \\
20091204\end{array}$} & \multirow{2}{*}{$\begin{array}{c}2009 \text { 年 } \\
\text { TM } \\
20011003\end{array}$} & \multicolumn{2}{|c|}{$\begin{array}{l}\text { WRS-2 } \\
\text { 轨道 }\end{array}$} & \multirow{2}{*}{$\begin{array}{c}\begin{array}{c}1970 \mathrm{~s} \\
\text { MSS }\end{array} \\
19761202\end{array}$} & \multirow{2}{*}{$\begin{array}{c}\begin{array}{c}1990 \mathrm{~s} \\
\text { TM }\end{array} \\
19901103\end{array}$} & \multirow{2}{*}{$\begin{array}{c}2000 \mathrm{~s} \\
\mathrm{ETM}^{+} \\
20001005\end{array}$} & \multirow{2}{*}{$\begin{array}{c}2009 \text { 年 } \\
\text { TM } \\
20091107\end{array}$} \\
\hline 138 & 35 & & & & & 141 & 39 & & & & \\
\hline 138 & 36 & 19761111 & 19901114 & 20090830 & 20011003 & 142 & 35 & 19761221 & 19901110 & 20001028 & 20090927 \\
\hline 138 & 37 & 9761111 & 19901114 & 20091110 & 20001016 & 142 & 36 & 19761115 & 19901110 & 20001028 & 20091130 \\
\hline 138 & 38 & 9761111 & 19901114 & 20091102 & 20001117 & 142 & 37 & 19761115 & 19891022 & 20001028 & 20091 \\
\hline 138 & 39 & 9761217 & 19910914 & 20091102 & 20001101 & 142 & 38 & 19761115 & 19901110 & 20001028 & 20091114 \\
\hline 139 & 35 & 19761112 & 19891102 & 20091125 & 20001007 & 142 & 39 & 19761203 & 19901110 & 20001215 & 20091114 \\
\hline 139 & 36 & 19761112 & 19911023 & 20091125 & 20001007 & 143 & 35 & 116 & 1992 & 104 & 200 \\
\hline 139 & 37 & 19761112 & 19921110 & 20091125 & 20001007 & 143 & 36 & 19761116 & 19891029 & 20001104 & 20091121 \\
\hline 139 & 38 & 19761112 & 19900630 & 20091125 & 20001108 & 143 & 3 & 19761116 & 19901117 & 20011022 & 20091121 \\
\hline 139 & 39 & 19761218 & 19891110 & 20091109 & 20001108 & 143 & 38 & 19761116 & 19901117 & 20001003 & 20091105 \\
\hline 140 & 34 & 19761219 & 19901011 & 20090929 & 20001030 & 143 & 39 & 19761116 & 19921021 & 20001003 & 20090908 \\
\hline 140 & 35 & 19761219 & 19901112 & 20090929 & 20001030 & 144 & 35 & 19761117 & 19900820 & 20001229 & 20091112 \\
\hline 140 & 36 & 19761201 & 19920930 & 20090929 & 20001030 & 144 & 36 & 19761117 & 19921012 & 20011114 & 20091112 \\
\hline 140 & 37 & 19761113 & 19920930 & 20090929 & 20001030 & 144 & 37 & 19761117 & 19901023 & 20001010 & 20091128 \\
\hline 140 & 38 & 19761113 & 19920930 & 20091031 & 20001030 & 144 & 38 & 19761117 & 19901023 & 20001010 & 20090925 \\
\hline 140 & 39 & 19761113 & 19920930 & 20091031 & 20001030 & 144 & 39 & 19761117 & 19901023 & 20001010 & 20091011 \\
\hline 141 & 34 & 19761202 & 19890913 & 20090920 & 20001122 & 145 & 36 & 19761206 & 19911017 & 20011020 & 20091002 \\
\hline 141 & 35 & 19761202 & 19901103 & 20090920 & 20000919 & 145 & 37 & 19761013 & 19921104 & 20001102 & 20091103 \\
\hline 141 & 36 & 19761202 & 19901103 & 20091022 & 20000919 & 145 & 38 & 19761013 & 19891112 & 20001102 & 20091103 \\
\hline 141 & 37 & 19761202 & 19901103 & 20091022 & 20001005 & 146 & 36 & 19761013 & 19921010 & 20001008 & 20090923 \\
\hline 141 & 38 & 19761202 & 19901103 & 20091022 & 20001005 & 146 & 37 & 19761206 & 19891018 & 20001008 & 20091025 \\
\hline
\end{tabular}

表 3 四期湖泊制图信息的分段统计

Tab. 3 Statistics of lake mapping results based on areas in the four periods

\begin{tabular}{|c|c|c|c|c|c|c|c|c|}
\hline \multirow{3}{*}{$\begin{array}{c}\text { 湖泊面积分段 } A \\
\left(\mathrm{~km}^{2}\right)\end{array}$} & \multicolumn{8}{|c|}{ 湖泊面积范围内的湖泊数量与总面积 $\left(\mathrm{km}^{2}\right)$} \\
\hline & \multicolumn{2}{|c|}{ MSS $1970 \mathrm{~s}$} & \multicolumn{2}{|c|}{ TM4-5 1990s } & \multicolumn{2}{|c|}{$\mathrm{ETM}^{+} 2000 \mathrm{~s}$} & \multicolumn{2}{|c|}{ TM5 2009 年 } \\
\hline & 数目 & 总面积 & 数目 & 总面积 & 数目 & 总面积 & 数目 & 总面积 \\
\hline $0.0045 \leqslant A \leqslant 0.018$ & - & - & 9790 & 81.25 & 12190 & 119.76 & 8423 & 87.94 \\
\hline $0.018<A \leqslant 0.05$ & 1191 & 36.55 & 3338 & 98.07 & 6029 & 176.54 & 5733 & 167.86 \\
\hline $0.05<A \leqslant 0.1$ & 681 & 47.84 & 1076 & 75.06 & 2124 & 147.88 & 2103 & 144.75 \\
\hline $0.1<A \leqslant 0.2$ & 504 & 70.47 & 703 & 98.41 & 1154 & 161.88 & 1152 & 159.97 \\
\hline $0.2<A \leqslant 0.5$ & 459 & 143.42 & 503 & 157.46 & 843 & 260.36 & 807 & 246.54 \\
\hline $0.5<A \leqslant 1.0$ & 213 & 148.44 & 210 & 148.38 & 346 & 276.08 & 361 & 252.12 \\
\hline $1.0<A \leqslant 2.0$ & 156 & 217.96 & 144 & 204.89 & 153 & 244.30 & 189 & 269.43 \\
\hline $2.0<A \leqslant 5.0$ & 142 & 450.86 & 134 & 415.66 & 188 & 596.71 & 179 & 574.85 \\
\hline $5.0<A \leqslant 10.0$ & 71 & 496.02 & 67 & 465.68 & 96 & 692.97 & 95 & 654.74 \\
\hline $10<A \leqslant 50$ & 142 & 3524.18 & 133 & 3125.32 & 168 & 3864.46 & 180 & 4233.65 \\
\hline $50<A \leqslant 100$ & 50 & 3631.94 & 50 & 3502.46 & 59 & 4099.51 & 55 & 3867.83 \\
\hline $100<A \leqslant 250$ & 27 & 3980.38 & 28 & 4189.06 & 34 & 4951.21 & 44 & 6319.06 \\
\hline $250<A \leqslant 400$ & 12 & 3625.73 & 12 & 3724.28 & 11 & 3442.77 & 11 & 3309.43 \\
\hline $400<A \leqslant 1000$ & 8 & 4208.12 & 7 & 4769.52 & 8 & 5154.30 & 11 & 6647.47 \\
\hline$A>1000$ & 3 & 4573.38 & 2 & 3670.04 & 2 & 3855.41 & 4 & 5380.24 \\
\hline
\end{tabular}

从表 3 还可以看出, 分段湖泊总面积曲线随单个湖泊面积增大呈上升的趋势, 而分段湖泊数量曲线呈 下降的趋势, 且两者在 $0.1 \mathrm{~km}^{2}<A \leqslant 0.2 \mathrm{~km}^{2}$ 分段上相交. 湖泊面积大于 $0.1 \mathrm{~km}^{2}$ 该分段,四期湖泊的分段湖 泊数量曲线逐渐靠近. 而对于分段面积曲线而言,1970s 的 MSS 湖泊图层与 1990s 的 TM 图层变化保持一致, $2000 \mathrm{~s}$ 的 $\mathrm{ETM}^{+}$图层与 2009 年的 TM 图层保持一致的变化. 从中可以明显地看出, 大于 $0.1 \mathrm{~km}^{2}$ 各个分段四 个时相的湖泊数量与总面积的差异明显减小. 为此, 本文以 $0.1 \mathrm{~km}^{2}$ 作为四个时期湖泊统一的制图精度, 相 当于对 MSS 图像中 30 个像元以上的湖泊以及 TM/ETM ${ }^{+}$图像 110 个以上像元的湖泊进行分析. 由此, 研究 
区内大于 $0.1 \mathrm{~km}^{2}$ 的湖泊数目在 $1976-2009$ 年的四个时段分别为 1787 、1993、3062 和 3088 , 对应湖泊总面积 依次为 $25070.90 、 24471.16 、 27599.96 、 31915.33 \mathrm{~km}^{2}$.

值得注意的是,由于高原内陆地区的湖泊变化剧烈,不同时期的同一湖泊面积可能在 $0.1 \mathrm{~km}^{2}$ 上下变 动. 因此, 多期湖泊数据的取舍原则为: (1) 保留四个湖泊图层中所有大于 $0.1 \mathrm{~km}^{2}$ 的湖泊; (2) 按照 2.2 节 的方法建立四期湖泊图层的空间关联, 保留所有与大湖 $\left(>0.1 \mathrm{~km}^{2}\right)$ 空间上关联的小湖.

\section{5 内陆湖泊变化分析}

\section{1 湖泊变化的总体趋势}

为了分析湖泊的时间变化过程, 对研究区域内 $0.1 \mathrm{~km}^{2}$ 以上的湖泊进行统计. 按照湖泊变化类型对图 2 四期湖泊变化图进行统计,得到各类湖泊变化的数量、湖泊扩张总面积 (扩张 + 新增的湖泊)、萎缩总面积 (干涸 + 萎缩的湖泊) 与累计变化总面积 $($ 表 4).

表 4 四个时段湖泊变化结果统计

Tab. 4 Statistics of lake change results in the four periods

\begin{tabular}{lrrrrrrrr}
\hline \multirow{2}{*}{ 变化时段 } & \multicolumn{9}{c}{ 湖泊变化的数量 } & \multicolumn{2}{c}{\begin{tabular}{c} 
扩张总面积 \\
\cline { 2 - 4 }
\end{tabular}} & 干涸 & 萎缩 & 稳定 & 扩张 & 新增 & $\begin{array}{c}\text { 萎缩总面积 } \\
\left(\mathrm{km}^{2}\right)\end{array}$ & $\begin{array}{c}\text { 变化总面积 } \\
\left(\mathrm{km}^{2}\right)\end{array}$ \\
\hline $1970 \mathrm{~s}-1990 \mathrm{~s}$ & 294 & 661 & 109 & 925 & 348 & 705.8 & 1314.6 & -552.4 \\
$1990 \mathrm{~s}-2000 \mathrm{~s}$ & 83 & 541 & 214 & 1486 & 878 & 3294.3 & 207.5 & 3150.5 \\
$2000 \mathrm{~s}-2009$ 年 & 280 & 870 & 173 & 2035 & 173 & 4696.0 & 488.7 & 4211.0 \\
$1970 \mathrm{~s}-2009$ 年 & 109 & 188 & 62 & 1767 & 1052 & 6915.9 & 96.3 & 6776.4 \\
\hline
\end{tabular}
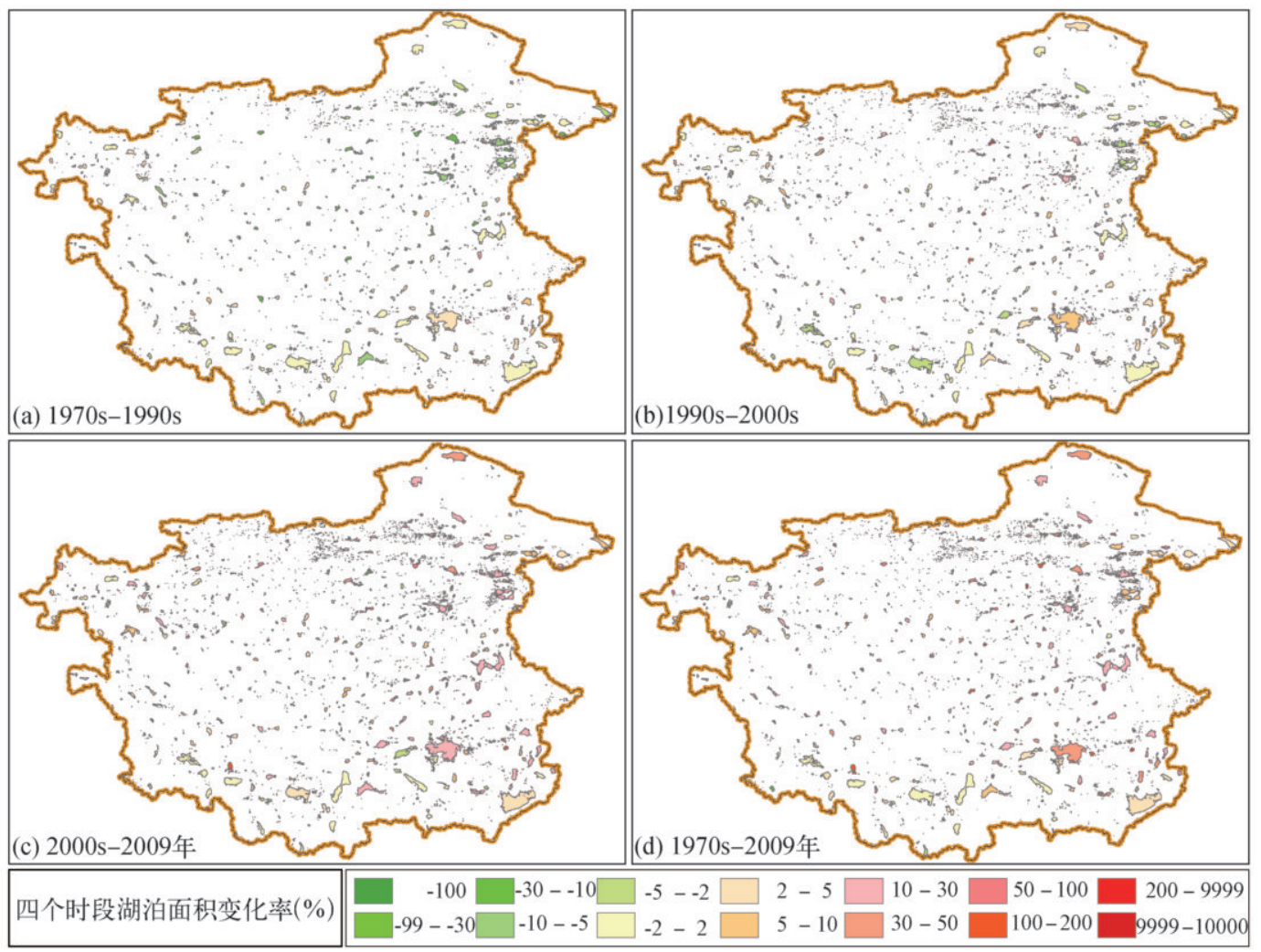

图 2 四个时段内陆湖泊的面积变化率

Fig. 2 Lake area change rates of inland lakes in the four periods 
从数量上看, 四个时段内扩张和新增的湖泊数量大于萎缩和干涸的湖泊数量, 而稳定的湖泊只占较小 的比例, 这表明近几十年来高原内陆湖泊变化较为频繁, 而湖泊数量的增加则表明总体上呈扩张的变化趋 势. 从面积上看, 湖泊在 $1970 \mathrm{~s}-1990 \mathrm{~s}$ 时段萎缩面积大于扩张面积, 湖泊总体上是萎缩的; 在 $1990 \mathrm{~s}-2000 \mathrm{~s}$ 和 2000s - 2009 年时段扩张面积大于萎缩面积, 湖泊总体上是扩张的; 且 $2000 \mathrm{~s}-2009$ 年时段湖泊萎缩与扩 张的面积都大于 $1990 \mathrm{~s}-2000 \mathrm{~s}$ 时段, 表明湖泊在 $1990 \mathrm{~s}-2009$ 年的两个时段呈加速扩展的趋势; 从 $1970 \mathrm{~s}-$ 2009 年全时段的湖泊变化来看,扩张的湖泊总面积远大于萎缩的总面积, 湖泊总面积变化率为 $27.3 \%$, 总体 上呈扩张的趋势.

\section{2 湖泊变化的时空特征}

在无外流的情况下, 封闭流域内水量的盈亏直接表现为流域内部湖泊面积的扩张与萎缩, 以封闭流域 内为单元分析湖泊面积的变化更能直观地反映内陆湖泊变化的时空特征. 为此, 本文按照内陆封闭流域对 湖泊进行区域划分, 以流域为单元统计流域内湖泊总面积的变化率, 生成 1970s - 1990s、1990s - 2000s、1970s $-2000 s 、 2000 s-2009$ 年、1990s -2009 年、1970s - 2009 年共 6 个时段的湖泊面积变化图, 分别描述湖泊变化 的时间过程和空间特征 (图 3 ). 由图可知:
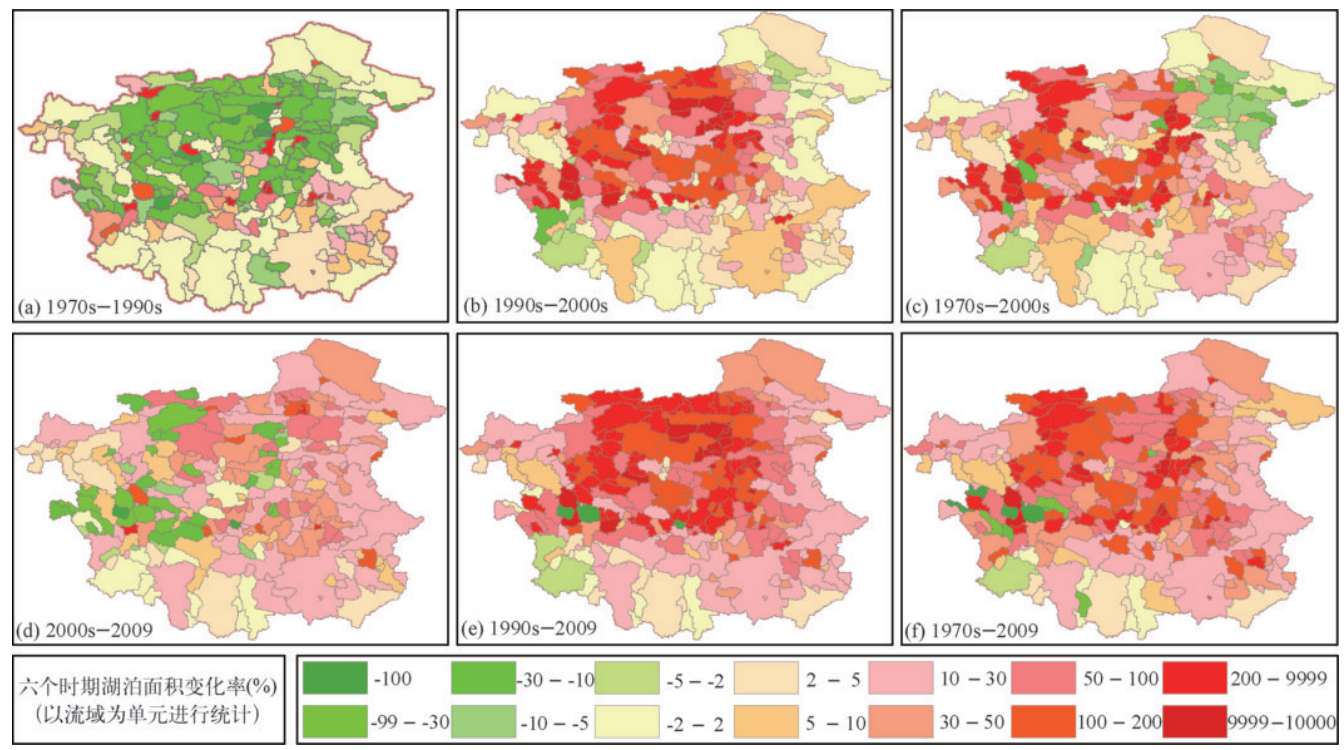

图 3 六个不同时段封闭流域内湖泊面积变化率

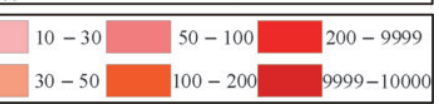

Fig. 3 Lake area change rates of inland lakes in closed basins in six different periods

（1）从时间过程上看,湖泊变化的时间过程可分为两个阶段, 1970s - 1990s 湖泊萎缩的阶段和 $1990 \mathrm{~s}-$ 2009 湖泊扩张的阶段. 1970s - 1990s 时段封闭流域内湖泊总面积同时出现湖泊萎缩、稳定与扩张的变化. 按 照表 1 对湖泊变化类型进行统计, 湖泊萎缩的流域 131 个, 扩张的流域 94 个,稳定的流域共 43 个,结合表 4 可知,该时段总体呈萎缩的趋势. 1990s - 2000s 时段湖泊主要表现为扩张的形态,共计 214 个流域出现扩张 的变化, 而稳定与萎缩的流域都较少, 分别为 37 个和 17 个. $2000 \mathrm{~s}-2009$ 年时段继续表现为扩张的形态, 其 中 207 个流域湖泊扩张, 47 个流域湖泊萎缩, 14 个流域湖泊稳定. 1990s -2009 年时段共 253 个流域出现湖 泊扩张的情形,稳定与萎缩的流域数量分别为 9 和 6 , 该时段湖泊表现总体上表现为扩张的形态. 1970s 2009 年全时段湖泊的变化以扩张为主, 共 250 个流域湖泊扩张, 稳定与萎缩的流域数量分别为 6 和 12 .

(2) 研究区域的中北部地区一藏北羌塘高原区是湖泊变化最为剧烈的地区, 呈先萎缩后扩张的形式. 湖 泊在 $1970 \mathrm{~s}-1990 \mathrm{~s}$ 时段剧烈萎缩, 而在 $1990 \mathrm{~s}-2000 \mathrm{~s}$ 时段急剧地扩张, 且湖泊变化明显高于其它地区. 结合 $1970 s-2000 s$ 时段该地区湖泊扩张的形态可知, 1990s - 2000s 时段的湖泊扩张面积大于 $1970 s-1990 \mathrm{~s}$ 时段 湖泊萎缩的面积. 在 $1990 \mathrm{~s}-2000 \mathrm{~s}$ 和 2000s - 2009 年两个时段湖泊主要呈急剧扩张的变化, 大部分区域湖泊 
面积变化率超过 $30 \%$.

(3) 研究区域南部及东西两侧的部分流域湖泊变化相对稳定. 冈底斯山北麓、昆仑山和喀喇昆仑山南 部的部分流域的湖泊, 如当惹雍错流域、杰萨错流域、帕龙错流域、昂拉仁错一仁青休布错流域等这些高山深 谷流域在近 30 多年来一直处于稳定的状态. 这些湖泊大多处于地势陡峭的区域或高山深谷内, 湖泊的变化 主要体现为水位的变化.

(4) 色林错流域及周边流域在 30 多年以来湖泊一直处于扩张的状态, 且湖泊面积变化率一直处于加速 的状态. 色林错在 $1970 \mathrm{~s}-2009$ 年的四个时期内的湖泊面积依次为 $1640.6 、 1716.0 、 1876.2$ 和 $2335.3 \mathrm{~km}^{2}$, 湖 泊面积扩张了 $42.3 \%$, 湖泊面积超过纳木错, 成为西藏最大的湖泊. 周边的巴木错流域、班戈错流域、兹格塘 错流域、乃日平错流域等也一直处于扩张的情形.

(5) 从湖泊变化的空间分布可以看出, 以冰川补给的为主的湖泊变化不及以地下水补给为主的湖泊. 根据青藏高原的冰川分布 ${ }^{[3]}$ 可知, 冰川主要分布在研究区两侧地区和南部地区, 如昆仑冰川、玉龙冰川、鱼 鳞冰川、各拉丹冬冰川、念青唐古拉山冰川、冈底斯山南麓冰川等, 这些冰川所在的流域和湖泊面积都较大, 这些冰川补给的湖泊具有稳定、充足的水源补给, 在 $1970 \mathrm{~s}-1990 \mathrm{~s}$ 时段湖泊整体萎缩的情况下依然保持相 对稳定, 而在 $1990 \mathrm{~s}-2009$ 年时段湖泊处于整体扩张的情形下,该区域湖泊的扩张变化程度又不及藏北芫塘 高原区的湖泊. 而㒸塘高原区的内流流域和湖泊面积都相对较小,大部分处于高原多年冻土地带,水源补给 主要为地下水,其补给的稳定程度也不及冰川, 因此在 $1970 \mathrm{~s}-1990 \mathrm{~s}$ 时段的低温期 ${ }^{[24]}$ 湖泊表现为剧烈萎 缩, 而在 1990 年后气温升高后又表现为急剧地扩张, 充分表明这些湖泊对气候变化更为敏感.

\section{6 结论}

本文主要从湖泊变化制图的角度研究了海量多时相 Landsat 系列数据支持下的青藏高原内陆湖泊变化 的信息提取技术与分析方法,讨论了内陆湖泊的季节变化因素和湖泊变化制图需注意的问题,并以封闭流 域为单元分析湖泊变化的时间过程和空间特征. 结论如下:

(1) 青藏高原内陆湖泊的季节性变化较大, 使用遥感数据研究高原内陆的湖泊变化需考虑季节因素的 影响,不同时段的湖泊面积比较需要选择湖泊相对稳定的季节. 通过对典型湖泊季节变化的分析表明, $9-$ 12 月是一年内湖泊处于相对稳定的时段之一, 湖泊最大面积变化率不超过 $2 \%$. 本文将其作为长时段湖泊 变化分析的最佳时段, 并以 $2 \%$ 为湖泊季节性变化与阶段性变化的分界点. 同时, 根据遥感数据的可得性和 降水观测资料,选定 1976 年、1990 年、2000 年和 2009 年 $9-12$ 月份的遥感数据为湖泊变化分析的主要数 据源.

(2) 通过对分段湖泊数量与湖泊面积变化的对比, Landsat MSS/TM/ETM ${ }^{+}$湖泊制图信息在 $0.1 \mathrm{~km}^{2}$ 以 上的湖泊的数量与面积统计表现较好的一致性, 故本文取大于 $0.1 \mathrm{~km}^{2}$ 的湖泊用于湖泊变化分析.

(3) 4 个时期内湖泊变化的结果表明,青藏高原内陆湖泊在近几十年内发生了剧烈的变化,湖泊变化的 时间过程和空间格局也具有一定的规律. 从时间过程来看, 湖泊总体上在 1970s - 1990s 时段萎缩, 在 1990s 2009 年的两个时段扩张, 湖泊总扩张率为 $27.3 \%$. 从空间格局来看, 藏北㒸塘高原地区湖泊变化最为剧烈, 近几十年出现剧烈萎缩和剧烈扩张的形态; 冈底斯山北麓、昆仑山和喀喇昆仑山南部部分地区的湖泊则保 持相对稳定的形态; 色林错和周边地区一直处于扩张形态. 湖泊变化这种空间模式与湖泊补给模式有关, 冰 川补给流域湖泊变化相对平稳,而地下水补给的湖泊变化较为剧烈.

致谢: Landsat 湖泊信息提取的过程中, 得到加州大学洛杉矶分校地理系学生 Luis, Mathhew Perterson 等在本 文的数据准备与湖泊编辑后处理上的帮助,特此致谢.

\section{7 参考文献}

[1] 王苏民,窦鸿身. 中国湖泊志. 北京:科学出版社, 1998: 580 .

[ 2 ] 陈志明. 青藏高原湖泊退缩及其气候意义. 海洋与湖沼,1986, 17 (3) : 208-216.

[ 3 ] 姚檀栋. 青藏高原及毗邻地区冰川湖泊图. 西安: 西安地图出版社, 2008.

[ 4 ] Harris AR. Time series remote sensing of a climatically sensitive lake. Remote Sensing of Environment, 1994, 50:83-94.

[ 5 ] 李世杰, 李万春,夏威岗等. 青藏高原现代湖泊变化与考察初步变化. 湖泊科学, 1998, 10(4) : 95-96. 
[6] 鲁安新, 姚檀栋, 王丽红等. 青藏高原典型冰川和湖泊变化遥感研究. 冰川冻土,2005, 27(6): 783-792.

[7] 边 多,杨志刚,李 林等. 近 30 年来西藏那曲地区湖泊变化对气候波动的响应. 地理学报, 2006, 61 (5): $510-518$.

[8] 邵兆刚,朱大岗,孟宪刚等. 青藏高原近 25 年来主要湖泊变迁的特征. 地质通报,2007, 26(12):1633-1645.

[9] 乔 程, 骆剑承,盛永伟等. 古今变化的遥感分析一一达则错为例. 湖泊科学, 2010, 22(1):98-102.

[10］杨日红,于学政,李玉龙. 西藏色林错湖面增长遥感信息动态分析. 国土资源遥感, 2003, 2 :64-67.

[11] Bian D, Li L, Wang W et al. The response of lake change to climate fluctuation in north Qinghai-Tibet Plateau in last 30 years. Journal of Geographical Sciences, 2009, 19(2) : 131-142.

[12] Liu J, Wang S, Yu S et al. Climate warming and growth of high-elevation inland lakes on the Tibetan Plateau. Global and Planetary Change, 2009, 67 : 209-217.

[13] Liu J, Kang S, Gong T et al. Growth of a high-elevation large inland lake, associated with climate change and permafrost degradation. Hydrology and Earth System Sciences, 2010, 14:481-489.

[14] Ye QH, Zhu P, Zheng HX et al. Glacier and lake variations in the Yamzhog Yumco basin, southern Tibetan Plateau from 1980 to 2000 using remote-sensing and GIS technologies. Journal of Glaciology, 2007, 53(183):673-676.

[15] Ye QH, Yao TD, Chen F et al. Response of glacier and lake covariations to climate change in Mapam Yumco Basin on Tibetan Plateau during 1974-2003. Journal of China University of Geosciences, 2008, 19(2) :135-145.

[16] 武慧智,姜琦刚,程 涁. 基于 RS 和 GIS 技术青藏高原湖泊动态变化研究. 世界地质,2007, 26(1):66-70.

[17] 张继承,姜琦刚,李远平等. 基于 RS 和 GIS 的西藏地区湖泊动态监测及气候背景. 地球科学与环境学报,2008, 30 (1) : $87-93$.

[18] 骆剑承,盛永伟,沈占锋等. 分步迭代的多光谱遥感水体信息高精度自动提取. 遥感学报,2009, 13(4):610-615.

[19] 李均力, 盛永伟, 骆剑承. 喜马拉雅山地区冰湖信息的遥感自动化提取. 遥感学报, 2011, 15(1):36-43.

[20] 秦伯强. 气候变化对内陆湖泊影响分析. 地理科学, 1993, 13(3): 212-219.

[21] Woodcock CE, Allen R, Anderson M et al. Free access to Landsat imagery. Science, 2008, 320 : $1011-1011$.

[22] Lehner B, Verdin K, Jarvis A. HydroSHEDS technical documentation. World Wildlife Fund US, Washington DC. 2006. ( http://hydrosheds. cr. usgs. gov).

[23] 韦志刚, 黄荣辉, 董文杰. 青藏高原气温和降水的年际和代际变化. 大气科学, 2003,27(2): 157-170.

[24] 林振耀,赵昕奕. 青藏高原气温降水变化的空间特征. 中国科学( D 辑: 地球科学),1996,26(4): 354-358. 